\section{BMJ Paediatrics Open}

\title{
ROP screening and treatment in four district-level special newborn care units in India: a cross-sectional study of screening and treatment rates
}

\author{
Shalinder Sabherwal (D , ${ }^{1}$ Clare Gilbert, ${ }^{2}$ Allen Foster, ${ }^{2}$ Praveen Kumar ${ }^{3}$
}

To cite: Sabherwal S, Gilbert C, Foster A, et al. ROP screening and treatment in four districtlevel special newborn care units in India: a cross-sectional study of screening and treatment rates. BMJ Paediatrics Open 2021;5:e000930. doi:10.1136/ bmjpo-2020-000930

Received 31 0ctober 2020 Revised 25 January 2021 Accepted 22 February 2021
Check for updates

(C) Author(s) (or their employer(s)) 2021. Re-use permitted under CC BY-NC. No commercial re-use. See rights and permissions. Published by BMJ.

${ }^{1}$ Community Ophthalmology, Dr Shroff's Charity Eye Hospital Delhi, New Delhi, Delhi, India ${ }^{2}$ Department of Clinical Research, Faculty of Infectious and Tropical Diseases, LSHTM, London, UK

${ }^{3}$ Pediatrics, PGIMER,

Chandigarh, Chandigarh, India

Correspondence to Dr Shalinder Sabherwal; shalinder.sabherwal@sceh.net

\section{ABSTRACT}

Objective Blindness from retinopathy of prematurity (ROP) in middle-income countries is generally due to absence of screening or inadequate screening. The objective of this study was to assess uptake of services in an ROP programme in four district-level special newborn care units in India.

Design Cross-sectional study.

Setting All four neonatal units of a state in India where model programme for ROP had been introduced

Patients Infants eligible for screening and treatment of ROP between March and May 2017.

Intervention Data on sex, birth weight and gestational age of eligible infants were collected and medical records reviewed for follow-up.

Main outcome measures Proportion of eligible infants screened and for those screened, age at first screening, completion of screening, diagnosis and treatment received if indicated. The characteristics of infants screened and not screened were compared.

Results $137(18 \%)$ of the 751 infants eligible for screening were screened at least once, with no statistically significant difference by sex. The mean birth weight and gestational age of those screened were significantly lower than those not screened. Among those screened, 43\% underwent first screening later than recommended and $44 \%$ had incomplete follow-up. Fourteen infants (11\% of those screened) were diagnosed with ROP. Five were advised laser treatment and all complied.

Conclusion Uptake, completion and timing of first screening was suboptimal. Some planned interventions including training of nursing staff, use of integrated datamanagement software and providing material for parent counselling, which have been initiated, need to be fully implemented to improve uptake of ROP screening services.

\section{BACKGROUND}

India, like many other middle-income countries, is facing an epidemic of retinopathy of prematurity (ROP), which is emerging as an important cause of childhood blindness. ${ }^{1}$ It has been estimated that approximately 10\% of 32200 infants who become blind or visually impaired worldwide every year live in India. ${ }^{2}$ There are several reasons for the increase in ROP blindness in India, including the recent

\section{What is known about the subject?}

Screening and urgent treatment of retinopathy of prematurity (ROP) is effective at preventing most blindness due to ROP.

- Most ROP blindness in preterm infants is due to lack of screening, inadequate screening or delayed screening.

- Few studies report the proportion of preterm infants eligible for ROP screening who complete screening in a timely manner.

\section{What this study adds?}

Despite systems to identify infants eligible for screening, only $18 \%$ got screened; among those $42.6 \%$ had delayed first screening and only $56.5 \%$ completed screening.

- More preterm, sicker infants were more likely to be screened than more mature, healthier infants.

- More robust systems are needed to ensure that all infants who require ROP screening are screened, particularly after discharge from the neonatal unit.

increase in the number of neonatal intensive care units (NICUs), which is increasing the survival of preterm infants. In some of these units, neonatal care may be of suboptimal quality, which can expose preterm infants to modifiable risk factors such as unregulated supplemental oxygen, sepsis and failure to gain weight. ${ }^{34}$ In many middle-income countries, ROP screening and treatment has not expanded commensurately, and the same applies to India where majority of ROP blind infants received care in NICUs without ROP services. ${ }^{56}$ For example, a study in eight states in India showed that only $30 \%$ of NICUs had regular ROP screening. ${ }^{7}$

Components of an ideal ROP programme include adherence to national guidelines and protocols, committed trained teams of health workers and engagement of parents. 
In India, the Ministry of Health and Family Welfare's Rashtriya Bal Swasthya Karakram programme for child health has drawn up screening criteria, which take account of the fact that in India larger and more mature babies develop ROP requiring treatment, ${ }^{910}$ up to $20 \%$ of whom would not have been screened if American criteria were followed. ${ }^{11}$ The current recommendations are that preterm infants or infants without known gestational age (GA) and with a birth weight (BW) up to $2000 \mathrm{~g}$ should be screened. ${ }^{12}$ Natural history of ROP requires the first screening to be at an appropriate interval after birth, according to national guidelines; in India, the recommendation is by chronological age of 30 days regardless of GA. ${ }^{12}$ This decision was made for three main reasons; first, except for a very small numbers the majority of these preterm infants develop ROP by $4-5$ weeks, ${ }^{13}$ second, it is easy for service providers and parents to understand and remember, and third, postmenstrual age cannot be used as GA is often unreliable. For a programme to be effective, it is important that all eligible infants are screened at the right time, which includes those who have been discharged or referred to a different unit, ${ }^{13}$ as failure to screen, or inadequate screening are important reasons why infants become blind from ROP despite a programme being in place. ${ }^{6} 14$

A recent programme, launched by the Ministry of Health in 2013, sought to address this, by building capacity in the government health system for ROP screening and treatment, focusing on infants admitted to special newborn care units (SNCUs) which now number more than 800 across the country. ${ }^{7}$ The programme, which ended in June 2019, was supported by the UK's Queen Elizabeth Diamond Jubilee Trust (the Trust) and was managed by Indian Institute of Public Health Hyderabad. In this programme, infants admitted to 20 SNCUs in 4 states who met the eligibility criteria recommended in the national ROP guidelines ${ }^{12}$ were screened in the SNCU, and discharged infants were asked to return to the same hospital for further screening, if indicated. In this study, four SNCUs in one of the four states were visited 4 months after initiation of the programme and data of the first 3 months were included. In three SNCUs, screening was performed by an ophthalmologist working in another hospital in the district who visited on a designated day and time of the week. In the other SNCU, the ophthalmologist worked in the same hospital and was called to screen when required. Details of all infants admitted in SNCUs are recorded in a separate register which is completed by the senior nurse in-charge on duty. A high proportion (more than 90\%) of SNCUs in the state also have a dedicated database with a data entry person. The data entered in the register and database includes date of admission, date of birth, BW, GA, diagnoses and date of discharge. However, no data on ROP screening or treatment are entered into the admissions register nor the database.

The overall purpose of this study was to undertake an early evaluation of the Trust supported ROP programme in one of the four states. The objectives were to assess the uptake of ROP screening and treatment among eligible infants where this was indicated, and to compare the characteristics of infants who were or were not screened. Results on the availability of equipment, and practices and attitudes regarding oxygen monitoring have already been published. ${ }^{15}$

\section{MATERIALS AND METHODS}

The state selected for the study reflects the demographic profile of India ${ }^{16}$ with an infant mortality rate within 'atrisk' level for an impending ROP epidemic. ${ }^{17}$ All four SNCUs, which were randomly coded A, B, C and D to maintain confidentiality, were visited by the primary investigator (SS). In each SNCU, permission was sought before collecting data. A designated ROP nurse in each $\mathrm{SNCU}$ with responsibilities for managing the programme including documenting the findings of screening in a separate register ('ROP register') and patient general nursing records, assisted in data collection.

Data for this cross-sectional study were collected for the months of March, April and May 2017. To identify the number of infants eligible for screening, data were extracted from the SNCU database (one unit) or from the admissions register (three units). Data for BW and GA were collected for all babies eligible for screening and comparisons were made between those screened and not screened. For all eligible babies, data on screening were extracted from records maintained by the ROP nurse for inpatient and outpatient screening (all units). Data on outpatient screening was also being maintained at SNCU A by the screening ophthalmologists. The following data were extracted, whether the infant had been screened at all, and if so, then at the first and each subsequent screening episode: the date of screening and the medical management decision, including the need for treatment, and whether this was adhered to.

\section{Definitions}

Eligibility for screening was defined according to the Indian national guidelines, that is, BW $\leq 2000 \mathrm{~g}$ or GA $<34$ weeks, or GA between 34 and 36 weeks if exposed to factors such as prolonged supplemental oxygen, respiratory distress syndrome or blood transfusions. ${ }^{12}$ An infant was designated as 'screened' if they were screened even once. Screening was considered complete if the last follow-up visit had been attended or if an infant had missed only one follow-up visit. Follow-up was considered incomplete if more than one screening follow-up visit had been missed. Compliance with treatment was also recorded.

\section{Patient and public involvement}

It was not appropriate or possible to involve patients or the public in the design, conduct, reporting or dissemination plans of our research. Uptake was derived from the previous 3 months records. Results would be disseminated 


\begin{tabular}{lll}
\hline $\begin{array}{l}\text { Table } 1 \\
\text { SNCU }\end{array}$ & Proportion of eligible infants screened by sex and \\
\hline Sex and SNCU & Total eligible & $\begin{array}{l}\text { Infants screened at } \\
\text { least once, } \mathbf{n}(\%)\end{array}$ \\
\hline $\begin{array}{l}\text { Sex* } \\
\text { Male }\end{array}$ & 399 & $77(19)$ \\
Female & 351 & $60(17)$ \\
SNCU & & \\
SNCU A & 150 & $23(15)$ \\
SNCU B & 198 & $36(18)$ \\
SNCU C & 249 & $58(23)$ \\
SNCU D & 154 & $20(13)$ \\
Total & 751 & $137(18)$ \\
\hline
\end{tabular}

*One infant was of indeterminate sex.

SNCU, special newborn care unit.

to the public indirectly through the learnings incorporated in the information and education material

\section{Data analysis}

Data were analysed using $\mathrm{R}$ software, V.3.6. Analysis included calculation of means and SD and proportions with CIs. Tests for comparisons included the t-test for unpaired data, $\chi^{2}$ tests and analysis of variance.

Authors adhered to the Strengthening the Reporting of Observational Studies in Epidemiology cross-sectional reporting guidelines. ${ }^{18}$

\section{RESULTS}

Seven hundred and fifty-one infants were eligible for screening, these included 33 infants more than 37 weeks GA but BW $<2000 \mathrm{~g} .53 \%$ of eligible infants were male. Their mean BW was 1792.6 (SD 473.5, range 500-3750) g and their mean GA was 33.5 (SD 2.7 range 24-39) weeks. A total of $137(18 \%)$ of the 751 infants were screened at least once, with no statistically significant difference by sex or SNCU (table 1).

Data for BW were missing for 1 screened and 6 nonscreened infants and the same for GA was missing for 2 screened and 13 non-screened infants. The mean BW of those screened was $1608.0 \mathrm{~g}$ (SD, 392.0) and those not screened was $1833.6 \mathrm{~g}$ (SD, 484.4); mean GA of those screened was 32.9 weeks (SD, 3.1) and those not screened was 33.6 weeks (SD, 2.6). Both BW and GA were significantly lower for those screened $(\mathrm{p}<0.001$ for $\mathrm{BW}$ and $\mathrm{p}<0.05$ for GA). 243 eligible neonates had a very low BW $(<1500 \mathrm{~g})$. A significantly higher proportion of these infants $(25 \%)$ were screened than those with a $\mathrm{BW}$ of more than $1500 \mathrm{~g}(15 \%, \mathrm{p}=<0.001)$.

Information on age at first screening was missing for 8 of the 137 infants screened at least once. The mean age at first screening overall was 30.3 (range 1-60) days, with no differences by sex or SNCU (table 2). Forty-three per cent of infants underwent first screening after the recommended chronological age of 30 days.

Among the 137 neonates screened, the follow-up data were missing for five infants and one infant who did not survive was excluded (table 3). Among the 131 infants with follow-up data, 57 (43\%) had incomplete follow-up. A higher proportion of female than male infants had incomplete follow-up but the difference was not statistically significant $(\mathrm{p}=0.19)$, and the differences in rates of incomplete follow-up between SNCUs was also not statistically significant.

Nine of the 137 infants were advised repeat screening because the retinal vessels were reported as being immature at the first examination with immature retinal vessels. Only one of these infants had complete the follow-up (rest were part of 57 incomplete follow-up). The overall screening and outcomes are depicted in figure 1.

Fourteen infants (11\% of those screened) were diagnosed with ROP (figure 1, table 4), one of whom did not survive. Five developed signs of type $1 \mathrm{ROP},{ }^{19}$ three in SNCU A and two in SNCU B. All were advised peripheral retinal laser ablation and all received treatment. Among the eight surviving infants with less severe ROP, six had complete follow-up and did not require treatment and two had incomplete follow-up (table 4).

The mean GA of the treated infants was 29.2 (range 28-32 weeks) and the mean BW was 1231 (range 930-1800) g (table 4). None fell outside the Indian BW screening criteria.

\section{DISCUSSION}

Our study was designed as an assessment of the Trust's ROP programme, after early interventions in four SNCUs in rural districts of one of the states in India. While some of the interventions planned in the programme, such as having a trained ROP nurse had been fully implemented, other interventions, including training of other nursing staff, use of dedicated software for data management and providing materials for parent counselling and education in the local language, had been initiated but were not fully implemented at the time of this study.

In our study, there was poor uptake of any screening among eligible infants, as more than $80 \%$ were not screened at all. Similar findings have been reported in other studies in India, in which less than $40 \%$ of eligible babies were screened. ${ }^{20}{ }^{21}$ In comparison, most studies from high-income countries report screening compliance to be at least $80 \%$, with most reporting rates in the range of $90 \%-95 \% .^{22-24}$

More than $40 \%$ of infants who were screened once and who required further screening did not complete the recommended number of visits. This attrition is much higher than in a study in rural southern India, which also identified failure to complete all screening as a major challenge, with failure to return for screening after infants were discharged from the unit being the main reason. ${ }^{19}$ Similar findings were reported in two 
Table 2 Mean age of infants (in days) at first screening in each of four special newborn care units (SNCU)

\begin{tabular}{|c|c|c|c|c|c|c|}
\hline \multirow[b]{2}{*}{ SNCU } & \multicolumn{2}{|l|}{ Male } & \multicolumn{2}{|l|}{ Female } & \multicolumn{2}{|l|}{ Total } \\
\hline & No screened & Mean days & No screened & Mean days & Nor screened & Mean days \\
\hline SNCU A & 6 & 26.3 & 15 & 25.1 & 21 & 25.4 \\
\hline SNCU B & 22 & 31.1 & 14 & 32.1 & 36 & 31.5 \\
\hline SNCU C & 35 & 30.0 & 21 & 32.2 & 56 & 30.8 \\
\hline SNCU D & 11 & 35.7 & 5 & 25.0 & 16 & 32.4 \\
\hline Total & 74 & 30.9 & 55 & 29.6 & 129 & 30.3 \\
\hline
\end{tabular}

studies, from Brazil and Argentina, ${ }^{25} 26$ where incomplete follow-up accounted for around half of screening failures.

A limitation of our study is that data were not collected on whether the infants had been discharged from the neonatal unit, or whether they had died or were transferred to another unit before the first screening was due. In addition, parents of infants not screened were not contacted as the ROP nurses reported that the contact details in the medical records were often either absent or incorrect. These factors mean that we can only speculate why screening rates were so low.

In our study, dedicated ROP nurses had been trained, as shown effective previously, ${ }^{27}$ with designated work of identification of infants eligible for screening, making preparations for screening including dilating the infants, maintaining records and counselling the parents. However, systems were not in place to identify and document infants eligible for screening. Lists were not being created systematically, the need for screening was not documented in the admissions register, and contact details were unreliable. A first step to improve the proportion of eligible infants who are screened, is to draw the attention of neonatologists and ophthalmologists involved in providing ROP screening to the fact that low access to screening can be a problem. Systems need to be put in place to ensure that all preterm babies eligible for screening are identified on admission to the neonatal unit, with clearly defined roles and responsibilities. This should include documenting and compiling lists of babies to be screened, and communicating this to parents and screening ophthalmologists. Ideally electronic systems should be used, but if these are not available, a diary-based system can be used, where the name and contact details are entered on the date for the first or subsequent screening. A separate paper register can be used to track attendance, or this can be done using readily available software such as Excel. Training neonatologists, neonatal nurses and ophthalmologists should include these important aspects of service delivery. Community health workers ${ }^{28}$ who focus on maternal and child health, could also be involved in ensuring screening after discharge.

In our study, the mean GA and BW of eligible infants were high, a high proportion of these infants were likely to have been discharged before 30 days. This is even more likely in overcrowded units, as if often the case in low-resource settings, where less preterm or sick infants are often discharged early. An effective way to increase the proportion of eligible infants who are screened, is to screen before discharge, even if this is a bit early. This identifies babies with mature retinal vessels who do not need further screening, and importantly, increases awareness among parents who comply better with follow-up thereafter, as previously demonstrated in India. ${ }^{21}$ Indeed, in our study, over half of the infants who were screened once went on to complete all subsequent screening.

In our study first screening was beyond 30 days in $40 \%$ of infants. A delay in the first screening has also been highlighted as a problem in some high-income countries. ${ }^{22} 29$ The implication of late screening is that the disease may progress beyond type 1 ROP before screening, particularly in the presence of aggressive posterior ROP, which is a frequent occurrence in India. ${ }^{30}$

Table 3 Proportion of screened infants with completed follow-up

\begin{tabular}{|c|c|c|c|c|c|c|}
\hline \multirow[b]{2}{*}{ SNCU } & \multicolumn{3}{|c|}{$\begin{array}{l}\text { Screened infants with } \\
\text { follow-up data Male }\end{array}$} & \multicolumn{2}{|l|}{ Female } & \multirow{2}{*}{$\begin{array}{l}\begin{array}{l}\text { Total completed } \\
\text { follow-up }\end{array} \\
\mathrm{N}(\%)\end{array}$} \\
\hline & $\mathbf{N}$ & $\begin{array}{l}\text { Total } \\
\text { Screened }\end{array}$ & $\begin{array}{l}\text { Completed } \\
\text { follow-up, n(\%) }\end{array}$ & $\begin{array}{l}\text { Total } \\
\text { Screened }\end{array}$ & $\begin{array}{l}\text { Completed } \\
\text { follow-up, } n(\%)\end{array}$ & \\
\hline SNCU A & 19 & 5 & $4(80)$ & 14 & $8(57)$ & $12(63)$ \\
\hline SNCU B & 35 & 21 & $16(76)$ & 14 & $9(64)$ & $25(71)$ \\
\hline SNCU C & 57 & 35 & $17(49)$ & 22 & $10(45)$ & $27(47)$ \\
\hline SNCU D & 20 & 13 & $9(69)$ & 7 & $1(14)$ & $10(50)$ \\
\hline Total & 131 & 74 & $46(62)$ & 57 & $28(49)$ & $74(57)$ \\
\hline
\end{tabular}

SNCU, special newborn care unit. 


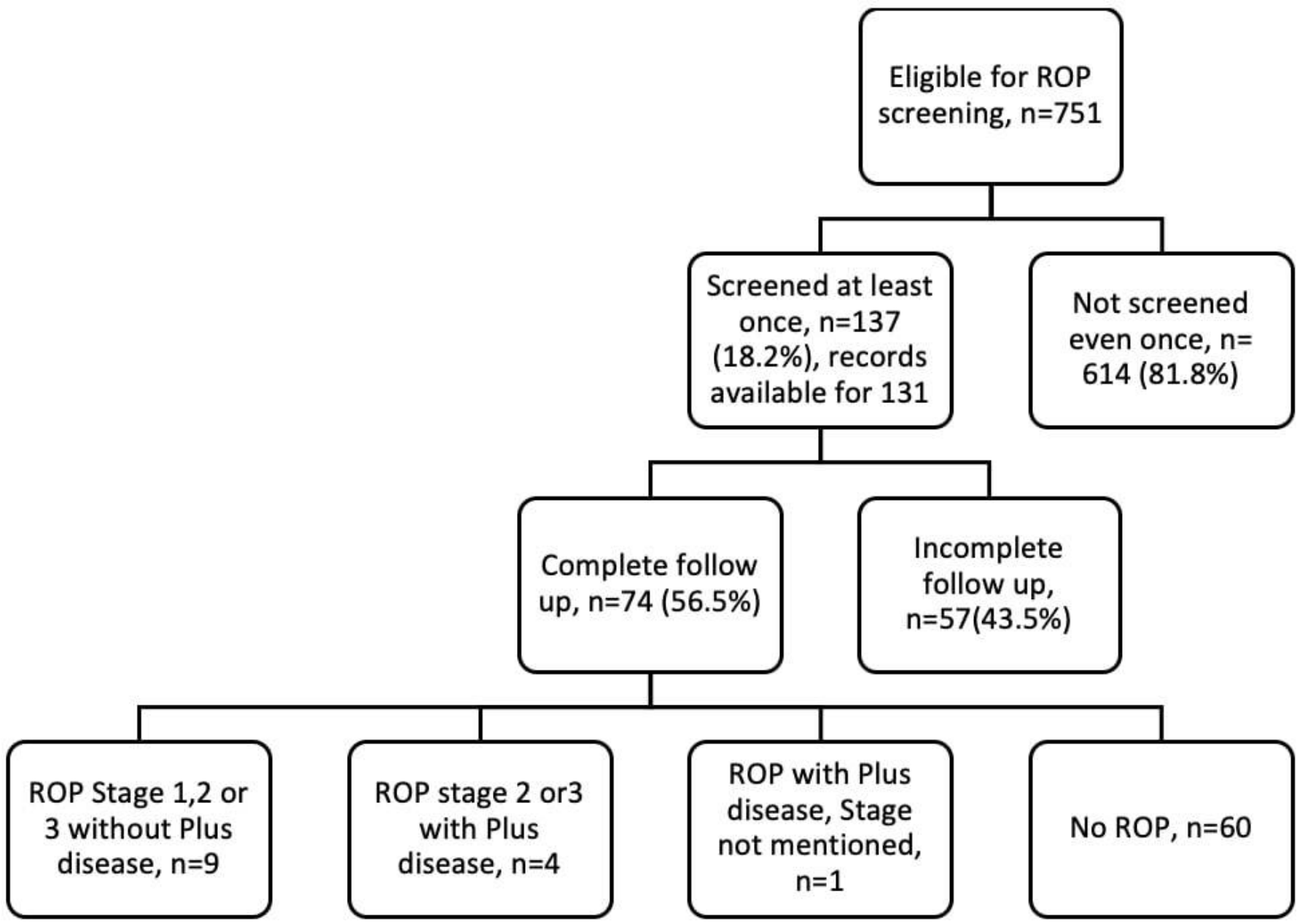

Figure 1 Flow diagram of screening coverage and outcomes. ROP, retinopathy of prematurity.

In our study, the GA and BW were significantly higher among infants not screened than those who were, which differs from two other studies, one in Argentina and the other in the UK, in which smaller, more premature babies were less likely to have been screened. ${ }^{22} 27$ Our finding has several possible explanations, one being that more preterm, sicker infants had a longer inpatient stay and were still inpatients at 30 days. Other explanations are that neonatal staff and/or parents may not have been convinced of the need for screening more mature, healthier babies. Although the staff was interviewed regarding oxygen practices, ${ }^{15}$ the attitudes of staff regarding screening and of parents not reporting for screening, was not captured in this study. Sicker and more preterm infants may have been transferred to another more advanced unit before the data of first screening as these SNCUs are level II NICUs. ${ }^{31}$ Transfer to another neonatal unit is an important reason for failure to screening in high income countries. ${ }^{32}$ However, data for transfer were not recorded in the SNCU or with the ROP nurse.

Any ROP was detected in approximately $10 \%$ of the infants screened in this study. This is less than the $20 \%-40 \%$ reported in other Indian studies. However, most of these studies were conducted either in a tertiary level centre ${ }^{33}$ or level III NICUs ${ }^{34} 35$ unlike the SNCUs in the present study, which are level II. As only very few of the eligible infants were screened in the study SNCUs, this incidence may not be truly representative of SNCU population. In our study, all preterm infants requiring treatment received treatment.

Although establishing ROP screening in district level SNCUs is an important first step, challenges such as inadequate uptake of screening, delayed first screening and incomplete follow-up were detected in our study SNCUs. We recommend that fields for ROP along with accurate contact details be included in the neonatal database which is used in many units in India, as this would provide a mechanism for identifying eligible babies and monitoring the uptake of screening among those who survive to 30 days. Robust systems and interventions are also required to ensure that all surviving eligible infants access screening in a timely manner. A further study, including interview of parents of infants who do not report for screening, is required in a large number of SNCUs to explore reasons for screening failures, that could lead to targeted interventions to increase uptake.

Acknowledgements Professor GVS Murthy, Director, Public Health Foundation of India, Dr Rajan Shukla, Associate professor, IIPH and the team at IIPH, Hyderabad 
Table 4 Characteristics of infants diagnosed with ROP and compliance with treatment and follow-up

\begin{tabular}{clllll}
\hline Birth weight & Gestational age & Sex & SNCU & Stage/plus disease* & Treatment \\
\hline $\begin{array}{c}\text { Type 1 ROP } \\
930\end{array}$ & 28 & F & A & Stage 3 with plus & Laser \\
1065 & 28 & F & A & Stage 3 with plus & Laser \\
1260 & 30 & M & A & Stage 2 with plus & Laser \\
1800 & 32 & M & B & Stage 3 with plus & Laser \\
1100 & 28 & M & B & Plus $†$ & Laser \\
\hline Less severe ROP & & & & & Follow-up Status \\
\hline 1100 & 28 & M & B & Preplus $\dagger$ & Died \\
1020 & 32 & F & A & Stage 2 & Incomplete \\
1600 & 34 & F & D & Stage 1 & Incomplete \\
\hline 920 & 28 & M & A & Stage 2 & Complete \\
1800 & 30 & F & A & Stage 2 & Complete \\
\hline 1100 & 28 & M & B & Stage 3 & Complete \\
1400 & 30 & M & C & Stage 2 & Complete \\
1700 & 38 & M & C & Stage 2 & Complete \\
1600 & 32 & F & D & Stage 2 & Complete \\
\hline
\end{tabular}

*No data on zone for any infant.

†No data on stage or zone.

ROP, retinopathy of prematurity; SNCU, special newborn care unit.

for the support during this study. Mr Atanu Majumdar for support during data analysis. Dr Hemant Sinha for support with logistics. Hooper Scholarship and LSHTM Trust Fund for support for travel and lodging.

Contributors SS: conceptualised and designed the study, designed the data collection instruments, collected data, carried out the initial analyses, drafted the initial manuscript and revisedthe manuscript; CG: conceptualised and designed the study, supervised the designing of data collection instrument and critically reviewed the manuscript for important intellectual content; AF: supervised the designing of the study and critically reviewed the manuscript for important intellectual content; PK: provided the inputs of the ongoing programme, provided intellectual content regarding neonatal care, supervised finalising the data collection instrument and reviewed the manuscript. All authors approved the final manuscript as submitted and agree to be accountable for all aspects of the work.

Funding The authors have not declared a specific grant for this research from any funding agency in the public, commercial or not-for-profit sectors.

Competing interests SS was involved in planning, conduct, reporting, conception and design, acquisition of data, analysis, interpretation and writing of the manuscript. CG was involved in planning, conception and design, interpretation of data and reviewing the manuscript. AF was involved in planning, concept and design and reviewing the manuscript and PK was involved in planning and reviewing the manuscript.

Patient and public involvement Patients and/or the public were not involved in the design, or conduct, or reporting, or dissemination plans of this research.

Patient consent for publication Not required.

Ethics approval The study was approved by the London School of Hygiene \& Tropical Medicine ethics committee and local ethical approval was obtained from the Institutional Ethics Committee, Indian Institute of Public Health, Hyderabad. Permission was also sought from the State National Health Mission (NHM).

Provenance and peer review Not commissioned; externally peer reviewed.

Data availability statement Data are available in a public, open access repository. Primary data of the infants eligible for screening in all 4 study SNCUs is available in data repository figshare.comlt can be accessed at https://figshare.com/ articles/dataset/ROP DATA xIsx/13012574/1sabherwal, shalinder (2020): ROP DATA.xlsx. figshare. Dataset. https://doi.org/10.6084/m9.figshare.13012574.v1.

Open access This is an open access article distributed in accordance with the Creative Commons Attribution Non Commercial (CC BY-NC 4.0) license, which permits others to distribute, remix, adapt, build upon this work non-commercially, and license their derivative works on different terms, provided the original work is properly cited, appropriate credit is given, any changes made indicated, and the use is non-commercial. See: http://creativecommons.org/licenses/by-nc/4.0/.

ORCID iD

Shalinder Sabherwal http://orcid.org/0000-0001-7687-0748

\section{REFERENCES}

1 Gilbert C, Rahi J, Eckstein M, et al. Retinopathy of prematurity in middle-income countries. Lancet 1997;350:12-14.

2 Blencowe H, Moxon S, Gilbert C. Update on blindness due to retinopathy of prematurity globally and in India. Indian Pediatr 2016;53 Suppl 2:S89-92.

3 Kalyan G, Moxon S. The role of neonatal nurses in the prevention of retinopathy of prematurity. Indian Pediatr 2016;53 Suppl 2:S143-50.

4 Neogi SB, Khanna R, Chauhan M, et al. Inpatient care of small and sick newborns in healthcare facilities. J Perinatol 2016;36:S18-23.

5 Azad R, Chandra P, Gangwe A, et al. Lack of screening underlies most Stage- 5 retinopathy of prematurity among cases presenting to a tertiary eye center in India. Indian Pediatr 2016;53 Suppl 2:S103-6.

6 Kulkarni S, Gilbert C, Zuurmond M, et al. Blinding retinopathy of prematurity in Western India: characteristics of children, reasons for late presentation and impact on families. Indian Pediatr 2018:55:665-70.

7 Gudlavalleti VS, Shukla R, Batchu T, et al. Public health system integration of avoidable blindness screening and management, India. Bull World Health Organ 2018:96:705-15.

8 Darlow BA, Gilbert CE, Quiroga AM. Setting up and improving retinopathy of prematurity programs: interaction of neonatology, nursing, and ophthalmology. Clin Perinatol 2013;40:215-27.

9 Shah PK, Narendran V, Kalpana N, et al. Severe retinopathy of prematurity in big babies in India: history repeating itself? Indian Pediatr 2009;76:801-4.

10 Vinekar A, Dogra MR, Sangtam T, et al. Retinopathy of prematurity in Asian Indian babies weighing greater than 1250 grams at birth: ten year data from a tertiary care center in a developing country. Indian $J$ Ophthalmol 2007;55:331-6.

11 Vinekar A, Jayadev C, Mangalesh S, et al. Role of tele-medicine in retinopathy of prematurity screening in rural outreach centers in India - a report of 20,214 imaging sessions in the KIDROP program. Semin Fetal Neonatal Med 2015;20:335-45. 
12 Dogra MR, Das P, Kekunnaya R. Screening of ROP. In: Singh AK, ed. Guidelines for universal eye screening in newborns including retinopathy of prematurity. New Delhi: RBSK, Ministry of Health Govt. of India, 2016: 35-41.

13 Jalali S, Anand R, Kumar H, et al. Programme planning and screening strategy in retinopathy of prematurity. Indian $J$ Ophthalmol 2003;51:89.

14 Zepeda-Romero LC, Meza-Anguiano A, Barrera-de León JC, et al. Case series of infants presenting with end stage retinopathy of prematurity to two tertiary eye care facilities in Mexico: underlying reasons for late presentation. Matern Child Health $J$ 2015;19:1417-25.

15 Sabherwal S, Gilbert C, Foster A, et al. Status of oxygen monitoring in four selected special care newborn units in India. Indian Pediatr 2020;57:317-20.

16 Census India. Estimates of mortality indicators, 2017. Available: https://www.censusindia.gov.in/vital_statistics/SRS_Report_2017/ 11.\%20Chap \%204-Estimates\%20of\%20Mortality\%20Indicators2017.pdf [Accessed Sep 2020].

17 Gilbert C. Retinopathy of prematurity: a global perspective of the epidemics, population of babies at risk and implications for control. Early Hum Dev 2008;84:77-82.

18 von Elm E, Altman DG, Egger M, et al. The strengthening the reporting of observational studies in epidemiology (STROBE) statement. 2007;18:800-4.

19 Early treatment for ROP cooperative group, et al. revised indications for the treatment of retinopathy of prematurity: results of the early treatment for ROP randomised trial. Arch Ophthalmol 2003;121:1684-94.

20 Vinekar A, Jayadev C, Mangalesh S, et al. Initiating retinopathy of prematurity screening before discharge from the neonatal care unit: effect on Enrolment in rural India. Indian Pediatr 2016;53 Suppl 2:S107-11.

21 Mehta P, Srivastava S, Aggrohiya D, et al. Quality improvement initiative to improve the screening rate of retinopathy of prematurity in Outborn neonatal intensive care graduates. Indian Pediatr 2018;55:780-3.

22 Wong HS, Santhakumaran S, Statnikov Y, et al. Retinopathy of prematurity in English neonatal units: a national population-based analysis using NHS operational data. Arch Dis Child Fetal Neonatal Ed 2014;99:F196-202.
23 Holmström GE, Hellström A, Jakobsson PG, et al. Swedish national register for retinopathy of prematurity (SWEDROP) and the evaluation of screening in Sweden. Arch Ophthalmol 2012;130:1418-24

24 Bain LC, Dudley RA, Gould JB, et al. Factors associated with failure to screen newborns for retinopathy of prematurity. $J$ Pediatr 2012;161:819-23.

25 Zin AA, Moreira MEL, Bunce C, et al. Retinopathy of prematurity in 7 neonatal units in Rio de Janeiro: screening criteria and workload implications. Pediatrics 2010;126:e410-7.

26 Urrets-Zavalia JA, Crim N, Knoll EG, et al. Impact of changing oxygenation policies on retinopathy of prematurity in a neonatal unit in Argentina. Br J Ophthalmol 2012;96:1456-61.

27 Vinekar A, Jayadev C, Dogra M, et al. Improving follow-up of infants during retinopathy of prematurity screening in rural areas. Indian Pediatr 2016;53 Suppl 2:S151-4.

28 Sai Kiranmayee P, Kalluri V. India to gear up to the challenge of "third epidemic" of retinopathy of prematurity in the world. Indian $\mathrm{J}$ Ophthalmol 2019;67:726-31.

29 Bain LC, Dudley RA, Gould JB, et al. Factors associated with failure to screen newborns for retinopathy of prematurity. $J$ Pediatr 2012;161:819-23.

30 Shah PK, Narendran V, Kalpana N. Aggressive posterior retinopathy of prematurity in large preterm babies in South India. Arch Dis Child Fetal Neonatal Ed 2012;97:F371-5.

31 Neogi SB, Malhotra S, Zodpey S, et al. Assessment of special care newborn units in India. J Health Popul Nutr 2011;29:500-9.

32 Ziakas NG, Cottrell DG, Milligan DW, et al. Regionalisation of retinopathy of prematurity $(\mathrm{ROP})$ screening improves compliance with guidelines: an audit of ROP screening in the Northern region of England. Br J Ophthalmol 2001;85:807-10.

33 Charan R, Dogra MR, Gupta A, et al. The incidence of retinopathy of prematurity in a neonatal care unit. Indian $J$ Ophthalmol 1995;43:123.

34 Hungi B, Vinekar A, Datti N, et al. Retinopathy of Prematurity in a rural Neonatal Intensive Care Unit in South India--a prospective study. Indian J Pediatr 2012;79:911-5.

35 Varughese S, Jain S, Gupta N, et al. Magnitude of the problem of retinopathy of prematurity. experience in a large maternity unit with a medium size level-3 nursery. Indian J Ophthalmol $2001 ; 49: 187$ 